\title{
Synthesis and Characterization of Nano Activated Carbon Tea Waste (Camellia sinensis L.) Viewed from the Content and Ratio of Orthophosphoric Acid
}

\author{
Daniel Ricky Putra Wijaya, Yohanes Martono, Cucun Alep Riyanto* \\ Program Studi Kimia, Fakultas Sains dan Matematika, Universitas Kristen Satya Wacana \\ *Corresponding author: cucun.alep@staff.uksw.edu
}

\begin{abstract}
Waste of tea is still limited in terms of utilization, potentially to be made into nanocarbon. In this research, nanocarbon synthesis from the waste of tea through carbonation method using furnace and purification with $\mathrm{HNO}_{3}$ with activator substance used is $\mathrm{H}_{3} \mathrm{PO}_{4}$. The specific objective of this study was to determine the optimal levels and ratios of ortho-phosphoric acid and to determine the properties and characteristics of nanocarbon from tea waste. Based on the Fourier-Transform Infra-Red (FT-IR) spectra, the best ortho-phosphate acid levels and ratios are $50 \%$ and 1:2 (w/w) $\mathrm{H}_{3} \mathrm{PO}_{4}$. The X-ray diffraction (XRD) analysis showed that the activated carbon dregs obtained were $C$ graphite which was characterized by the diffraction peak at 2theta: $26.2^{\circ} ; 26.5^{\circ} ; 42.2^{\circ} ; 42.4^{\circ}$; and $44.3^{\circ}$. Based on the Transmission Electron Microscope (TEM) image obtained shows that the activated carbon of the resulting tea waste has a particle size of 20-40 $\mathrm{nm}$.
\end{abstract}

Keywords: Activated carbon, nanocarbon, ortho-phosphoric acid, tea

\begin{abstract}
Abstrak
Limbah ampas teh yang masih terbatas dalam hal pemanfaatannya, berpotensi untuk dibuat menjadi nano karbon. Pada penelitian ini akan dilakukan sintesa nano karbon dari limbah ampas teh melalui metode karbonisasi menggunakan furnace dan pemurnian dengan $\mathrm{HNO}_{3}$ dengan zat aktivator yang digunakan adalah $\mathrm{H}_{3} \mathrm{PO}_{4}$. Tujuan khusus dari penelitian ini adalah menentukan kadar dan rasio asam orto-fosfat optimal serta menentukan sifat dan karakteristik nano karbon dari ampas teh. Berdasarkan spektra Fourier-Transform Infra-Red (FT-IR), kadar dan rasio asam orto-fosfat terbaik adalah $50 \%$ dan $1: 2$ (b/b) $\mathrm{H}_{3} \mathrm{PO}_{4}$. Hasil analisis x-ray diffraction (XRD) menunjukkan bahwa karbon ampas teh teraktivasi yang diperoleh adalah $\mathrm{C}$ graphite yang ditandai puncak difraksi pada 2theta: 26, $2^{\circ} ; 26,5^{\circ} ; 42,2^{\circ} ; 42,4^{\circ}$; dan $44,3^{\circ}$. Berdasarkan citra Transmission Electron Microscope (TEM) yang diperoleh menunjukkan bahwa karbon teraktivasi ampas teh yang dihasilkan memiliki ukuran partikel 20-40 nm.
\end{abstract}

Kata kunci: Ampas teh, asam-orto fosfat, karbon teraktivasi, nano karbon

\section{Pendahuluan}

Perkembangan teknologi saat ini

sudah memasuki teknologi nano,

memanfaatkan bahan yang berukuran nano meter $\left(10^{-9} \mathrm{~m}\right)$ yang dapat diaplikasikan pada berbagai aspek, seperti bidang kimia, biologi, kedokteran, material, elektronika, 
dan lain-lainnya. Keunggulan utama nano teknologi dengan ukurannya yang kecil adalah munculnya fungsi suatu zat pada skala nano (Pari et al., 2013). Nano karbon merupakan salah satu nanomaterial yang sangat luas aplikasinya. Pada perkembangannya, nano karbon merupakan karbon teraktivasi yang berukuran nano dengan bahan baku yang dapat berasal dari arang hasil karbonisasi, salah satunya karbonisasi lignoselulosa yang terdapat pada tanaman teh. Pemanfaatan teh masih terbatas dan dalam ruang lingkup yang kecil. Bidang peternakan menggunakan teh sebagai tambahan dalam pembuatan kompos (Syaifudin, 2013) dan tambahan dalam pakan ternak (Manullang, 2010). Sebagai bahan baku adsorben alternatif, ampas teh telah digunakan untuk menjerap ion logam dengan keefektifan sampai 100\% (Mahvi et al., 2005).

Limbah ampas teh sangat berpotensi dalam pembuatan karbon teraktivasi. Dalam pembuatan karbon teraktivasi, kandungan ampas teh yang diperhitungkan adalah holoselulosa yaitu sebesar $60,81 \%$. Ampas teh terdiri dari selulosa sebesar $29,42 \%$, lignin sebesar $36,94 \%$, dan abu sebesar $4,53 \%$, dan ekstraktif 15,22\% (Tutuş et al., 2015). Berdasarkan penelitian yang telah dilakukan (Ahmaruzzaman and
Laxmi Gayatri, 2010), ampas teh yang telah diaktivasi dan dikarbonisasi menghasilkan kadar karbon tetap yang relatif tinggi yakni $57,1 \%$. Pada proses pembuatan nano karbon dilakukan dengan menambahkan zat aktivator karena proses aktifasi merupakan hal penting yang perlu diperhatikan disamping bahan baku yang digunakan.

Tahap aktivasi nano karbon dapat dipengaruhi beberapa faktor diantaranya suhu karbonisasi, jenis aktivator, konsentrasi aktivator, dan waktu aktivasi. Aktivator yang baik digunakan untuk material lignoselulosa adalah aktivator yang bersifat asam, seperti $\mathrm{ZnCl}_{2}$ dan $\mathrm{H}_{3} \mathrm{PO}_{4}$ dibandingkan dengan aktivator yang bersifat basa, seperti $\mathrm{KOH}$. Hal ini dikarenakan material lignoselulosa memiliki kandungan oksigen tinggi dan aktivator asam bereaksi dengan gugus fungsi yang mengandung oksigen (Adinata, 2013).

Pada penelitian ini, zat aktivator nano karbon dari ampas teh yang digunakan yaitu $\mathrm{H}_{3} \mathrm{PO}_{4}$. Karbon yang terbentuk hasil dari karbonisasi masih mengandung zat yang masih menutupi pori-pori permukaan, oleh karena itu zat yang menutupi pori dihilangkan dengan menggunakan aktivator $\mathrm{H}_{3} \mathrm{PO}_{4}$. Hilangnya zat tersebut 
dari permukaan akan menyebabkan pori yang semakin besar pada karbon aktif. Besarnya pori meningkatkan luas permukaan karbon aktif (Najma, 2012). Penelitian yang dilakukan oleh (Güler $e t$ al., 2017) menyebutkan bahwa hasil karbon yang dihasilkan dari ampas teh akan meningkat jika suhu karbonisasi meningkat dan waktu karbonisasi yang semakin lama. Kandungan karbon pada suhu karbonisasi $400^{\circ} \mathrm{C}$ selama 30 menit akan menghasilkan 62,24\%, pada suhu $800^{\circ} \mathrm{C}$ selama 30 menit akan menghasilkan karbon $72,14 \%$, sedangkan pada suhu $800^{\circ} \mathrm{C}$ selama 120 menit akan menghasilkan karbon 82,54\%. Karbon akan memiliki surface area yang lebih luas dan menjadi stabil jika ukurannya diperkecil menjadi nano.

Pada penelitian (Shamsuddin et al., 2016) telah dilakukan sintesis dan karakterisasi karbon teraktivasi dengan zat aktivator $\mathrm{H}_{3} \mathrm{PO}_{4}$. Berdasarkan penelitian tersebut perlu dilakukan sintesis nano karbon terhadap kadar dan rasio zat aktivator $\mathrm{H}_{3} \mathrm{PO}_{4}$ yang kemudian akan ditentukan sifat dan karakteristiknya. Penelitian ini bertujuan untuk mensintesis nano karbon dari ampas teh ditinjau dari kadar dan rasio asam orto-fosfat serta menentukan sifat dan karakteristik nano karbon dari ampas teh.

\section{Metode Penelitian}

\section{Waktu dan Tempat Penelitian}

Penelitian ini dilaksanakan pada bulan November 2017 - Februari 2018 di Laboratorium Kimia, Fakultas Sains dan Matematika, Universitas Kristen Satya Wacana.

\section{Bahan dan Piranti}

Sampel limbah ampas teh. Bahan yang digunakan meliputi $\mathrm{H}_{3} \mathrm{PO}_{4}, \mathrm{HNO}_{3}$ dan $\mathrm{NaOH}$. Semua bahan yang digunakan berderajat PA (Pro-Analysis) diperoleh dari E-Merck Germany.

Piranti yang digunakan dalam penelitian ini adalah spektrofotometer inframerah (Shimadzu FTIR Prestige 21), Difraktometer Sinar-X (Rigaku Miniflex 600), Transmission Electron Microscope (TEM JEM 1400 JEOL/EO), neraca dengan ketelitian 0,01 g (Ohaus TAJ601), neraca analitis dengan ketelitian $0,1 \mathrm{mg}$ (Ohaus PA214), pH meter (Hanna HI 9812), furnace (Vulcan A-550), serta seperangkat piranti gelas. 
Preparasi Sampel (Güler et al., 2017) yang dimodifikasi

Seberat $100 \mathrm{~g}$ ampas teh dicuci dengan akuades panas kemudian dikeringkan 4 jam $\left(\mathrm{T}=105^{\circ} \mathrm{C}\right)$. Setelah kering, sampel dihaluskan dan diayak dengan ayakan ukuran 30 mesh.

Karbonisasi Sampel (Shamsuddin et al., 2016) yang dimodifikasi

Karbonisasi sampel dilakukan dengan memasukkan sampel ke dalam furnace $\left(\mathrm{T}=800^{\circ} \mathrm{C}\right)$ selama 2 jam. Karbon diimpregnasi dalam $10 ; 20 ; 30 ; 40$; dan $50 \%$ orto $\mathrm{H}_{3} \mathrm{PO}_{4}$ dengan rasio $1: 1 ; 1: 2 ; 1: 3$; 1:4; dan 1:5 (b/b) selama 24 jam. Setelah itu sampel disaring dengan vakum buchner dan dioven $\left(\mathrm{T}=105^{\circ} \mathrm{C}\right)$ semalam. Kemudian diaktivasi selama satu jam $\left(\mathrm{T}=500^{\circ} \mathrm{C}\right.$ ) lalu dicuci dengan $\mathrm{NaOH} 1 \mathrm{M}$ dan dibilas dengan akuades sampai pH 7. Karbon aktif dipanaskan dengan oven $\left(\mathrm{T}=110^{\circ} \mathrm{C}\right)$ selama 24 jam.

\section{Pemurnian Sampel (Subagio et al., 2013) yang dimodifikasi}

Karbon aktif direfluks selama 4 jam dengan pelarut $65 \% \quad \mathrm{HNO}_{3} \quad\left(\mathrm{~T}=100^{\circ} \mathrm{C}\right)$ kemudian dicuci dengan aquades hingga $\mathrm{pH}$ 7. Setelah itu dikeringkan semalam $\left(\mathrm{T}=110^{\circ} \mathrm{C}\right)$. Karbon aktif yang telah dikeringkan kemudian dihaluskan dan diayak dengan ayakan ukuran 120 mesh.

\section{Karakterisasi Sampel}

Analisa gugus fungsional nano karbon dapat diamati dengan Spektrofotometer Inframerah (FTIR) pada bilangan gelombang 4000-400 $\mathrm{cm}^{-1}$. Analisa sifat kristal dari hasil diuji dengan Difraktometer Sinar-X (XRD) dan untuk mengetahui ukuran partikel dari hasil dilakukan dengan menggunakan Transmission Electron Microscopy (TEM) pada hasil dari pengoptimalan kadar dan rasio zat aktivator.

\section{Analisa Data}

Analisis data IR, XRD, dan TEM rendemen nano karbon dari ampas teh yang ditinjau dari kadar dan rasio asam ortofosfat dilakukan secara deskriptif.

\section{Hasil Dan Pembahasan \\ Identifikasi Gugus Fungsi}

Karbon teraktivasi dari ampas teh dianalisis menggunakan FTIR untuk mengetahui gugus fungsi yang ada dan gugus organik yang hilang setelah diaktivasi. Hasil karakterisasi FTIR karbon teraktivasi dengan perlakuan variasi kadar Asam Orto-Fosfat dapat dilihat pada Gambar 1 dan variasi rasio perbandingan karbon teraktivasi dengan Asam OrtoFosfat dapat dilihat pada Gambar 2. 


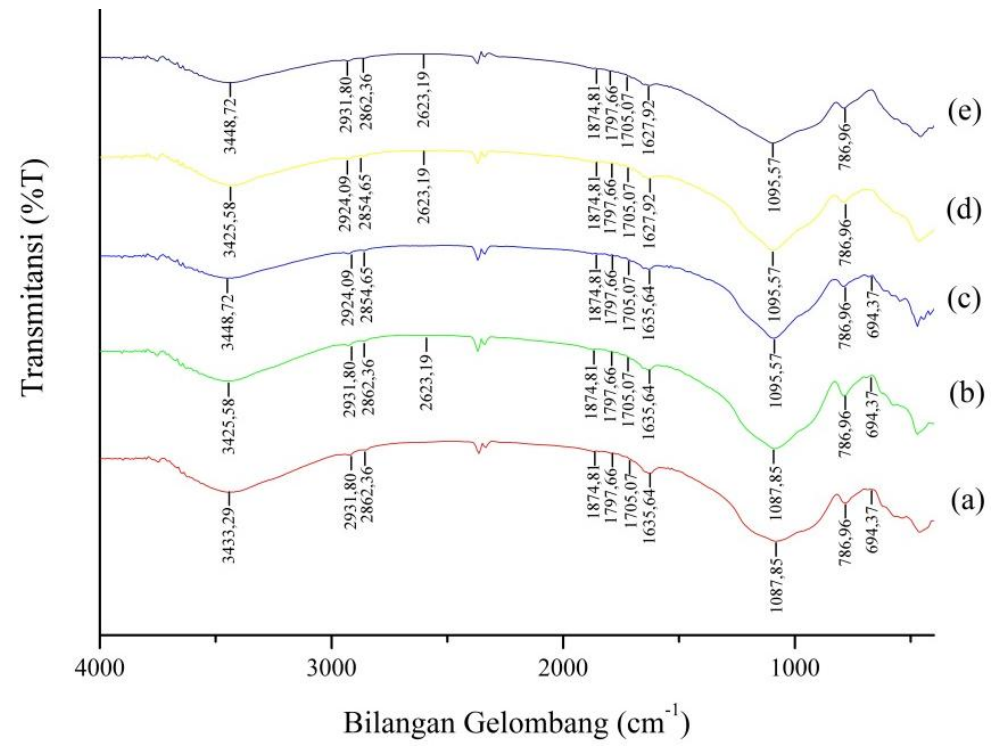

Gambar 1. Spektra FT-IR Karbon Ampas Teh Teraktivasi dengan Kadar $\mathrm{H}_{3} \mathrm{PO}_{4}$ : a) 10\%; b) 20\%; c) 30\%; d) $40 \%$; dan e) $50 \%$

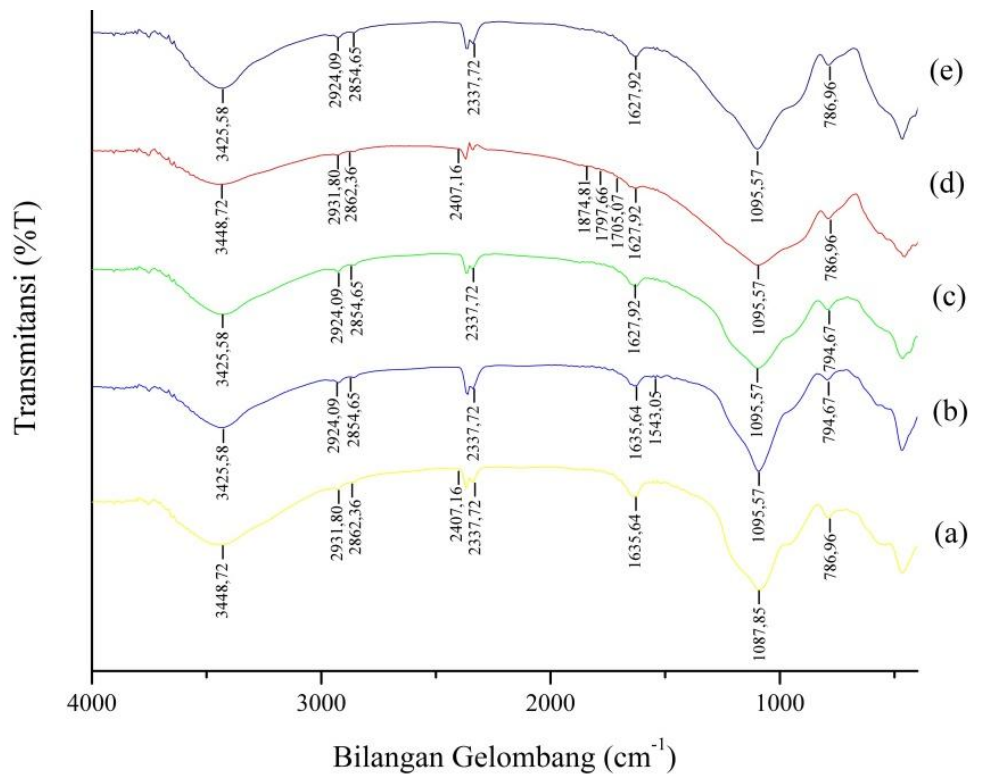

Gambar 2. Spektra FT-IR Karbon Ampas Teh Teraktivasi dengan rasio $\mathrm{H}_{3} \mathrm{PO}_{4}$ (b/b): a) 1:1; b) 1:2; c) 1:3; d) $1: 4 ;$ dan $1: 5$

Hasil analisis FT-IR pada Gambar 1 dan Gambar 2 menunjukkan beberapa serapan gugus senyawa organik pada karbon ampas teh teraktivasi. Pada Gambar 1 terlihat pita serapan pada bilangan gelombang 3448-3433 $\mathrm{cm}^{-1}$ yang merupakan gugus fungsi $\mathrm{OH}$ dalam kelompok hidroksil, diikuti serapan pada bilangan gelombang 1095-1087 $\mathrm{cm}^{-1}$ yang merupakan adanya vibrasi $\mathrm{C}-\mathrm{O}$ dari $\mathrm{OH}$ 
sekunder. Serapan pada bilangan gelombang 2931-2924 $\mathrm{cm}^{-1}$ dan $2854 \mathrm{~cm}^{-1}$ menunjukkan adanya vibrasi $\mathrm{C}-\mathrm{H}$ aldehida, juga pada pita 1635-1627 $\mathrm{cm}^{-1}$ yang merupakan peregangan $\mathrm{C}=\mathrm{O}$ (Sastrohamidjojo, 2001). Serapan melebar pada daerah bilangan gelombang $2623 \mathrm{~cm}^{-1}$ diduga adalah vibrasi dari $\mathrm{OH}$ pada gugus P-OH diikuti serapan pada daerah bilangan gelombang $1705 \mathrm{~cm}^{-1}$ yang diduga vibrasi dari gugus $\mathrm{P}=\mathrm{O}$ (Sahara et al., 2017). Selain itu, terdapat gugus fungsi yang hilang akibat dari semakin tingginya konsentrasi $\mathrm{H}_{3} \mathrm{PO}_{4}$ yang digunakan pada bilangan gelombang $694 \mathrm{~cm}^{-1}$ yang menunjukkan perenggangan gugus $\mathrm{C}-\mathrm{O}-\mathrm{C}$ (eter, ester, dan fenol) (Nasri et al., 2015).

Dari Gambar 2 terdapat pita serapan pada bilangan gelombang $1543 \mathrm{~cm}^{-1}$ yang menunjukkan gugus $\mathrm{C}=\mathrm{C}$ cincin aromatik, juga serapan pada bilangan gelombang $794-786 \mathrm{~cm}^{-1}$ yang menunjukkan vibrasi C$\mathrm{H}$ aromatic (Wibowo et al., 2011). Sementara itu terbentuknya serapan baru pada bilangan gelombang $2337 \mathrm{~cm}^{-1}$ adalah serapan gugus asetilen $(\mathrm{C} \equiv \mathrm{C})$ (Shamsuddin et al., 2016).

Hasil terbaik dari konsentrasi dan rasio $\mathrm{H}_{3} \mathrm{PO}_{4}$ yang digunakan pada Gambar 1 dan Gambar 2 adalah $50 \% \quad \mathrm{H}_{3} \mathrm{PO}_{4}$ dengan rasio 1:2 (b/b) karena dapat menghilangkan gugus fungsi $\mathrm{P}-\mathrm{OH}, \mathrm{OH}$ karboksilat, $\mathrm{C}=\mathrm{O}$ karboksilat dan $\mathrm{P}=\mathrm{O}$ pada bilangan gelombang 2623, 2407, 1874-1797, dan $1705 \mathrm{~cm}^{-1}$. Senyawa tar terbentuk dari keberadaan lignin yang dapat dihilangkan dengan aktivator $\mathrm{H}_{3} \mathrm{PO}_{4}$ (Adinata, 2013). Semakin tinggi konsentrasi aktivator yang digunakan maka semakin kuat ikatan dengan senyawa tar sisa karbonisasi dan dikeluarkan melewati mikro pori-pori karbon sehingga permukaan karbon semakin berpori yang berpotensi menyebabkan semakin besarnya daya adsorpsi karbon teraktivasi (Fitria and Tjahjani, 2016).

Hasil identifikasi dengan spektrofotometer inframerah ini menunjukkan bahwa karbon teraktivasi yang berasal dari ampas teh dengan aktivator asam orto-fosfat mengandung gugus fungsi $\mathrm{O}-\mathrm{H}, \mathrm{C}-\mathrm{O}, \mathrm{C}-\mathrm{H}, \mathrm{C}=\mathrm{C}, \mathrm{C}=\mathrm{O}$ dan $\mathrm{C} \equiv \mathrm{C}$. Adanya ikatan $\mathrm{OH}$ dan $\mathrm{C}-\mathrm{O}$ menunjukkan bahwa karbon teraktivasi yang dihasilkan cenderung bersifat lebih polar. Dengan demikian karbon teraktivasi yang dihasilkan dapat digunakan sebagai adsorben zat yang cenderung polar seperti untuk penjernihan air, gula, alkohol, atau sebagai penyerap emisi formaldehid (Wibowo et al., 2011). 


\section{Analisa XRD}

Analisis XRD dilakukan untuk mengidentifikasi fase kristal, struktur kristal, maupun kristalinitas dari sampel (Hartini et al., 2015). Sampel yang digunakan untuk analisa XRD yaitu 50\% $\mathrm{H}_{3} \mathrm{PO}_{4}$ dengan rasio 1:2 (b/b). Pada karakterisasi menggunakan XRD diamati difraktogram sampel sintesa karbon teraktivasi ampas teh yang ditunjukkan pada Gambar 3. Penampilan latar belakang difraksi yang luas, intensitas latar yang tidak teratur dan tidak adanya puncak yang tajam mengungkapkan struktur yang sangat amorf.

Pada profil karbon teraktivasi tampak sederhana dan hanya memperlihatkan dua pita difraksi luas dalam rentang sudut $(2 \theta=$ $22-30^{\circ}$ dan $43-48^{\circ}$ ) (Girgis et al., 2007). Pada Gambar 3, nampak C graphite sintesa memiliki kesamaan dengan $\mathrm{C}$ graphite standard pada peaks $26,2^{\circ}, 26,5^{\circ}$, $42,2^{\circ}, 42,4^{\circ}$, dan $44,3^{\circ}$. Akan tetapi, C graphite sintesa menunjukkan puncak yang lebih terpisah dan intensitas relatif lebih rendah daripada $\mathrm{C}$ graphite standard.

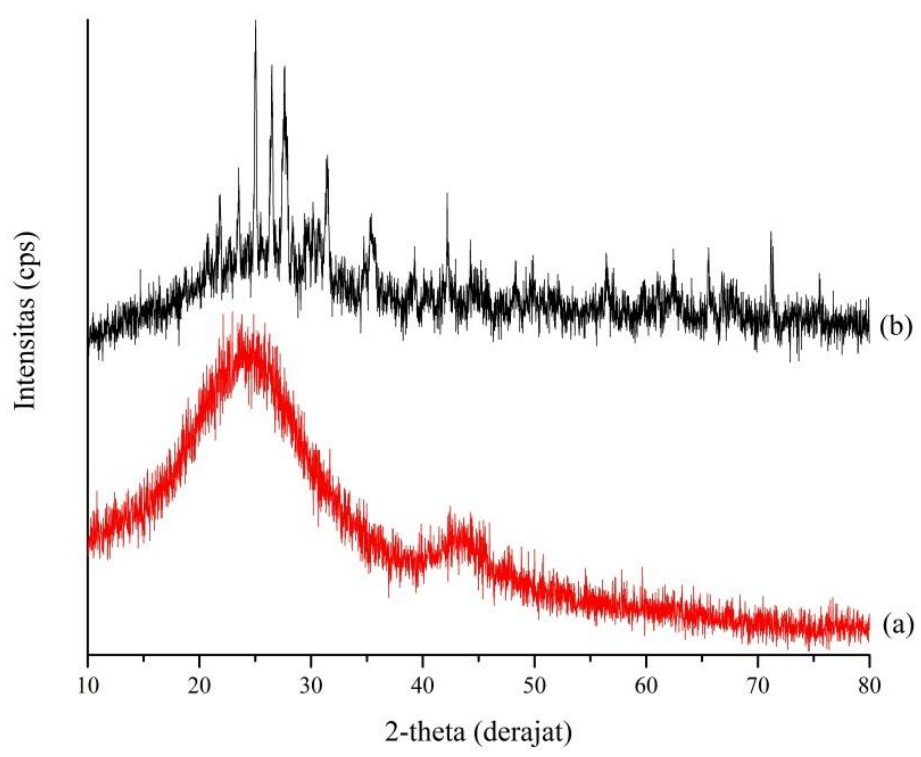

Gambar 3. Difraktogram Sinar-X Karbon Teraktivasi Standard (a) dan Karbon Ampas Teh Teraktivasi (b) Analisa TEM

Analisis TEM dilakukan untuk mengetahui ukuran partikel dari karbon teraktivasi ampas teh, hasil TEM karbon teraktivasi ampas teh disajikan pada Gambar 4. Berdasarkan hasil analisa TEM terlihat bahwa terdapat struktur yang tidak homogen pada beberapa bagian dan ukuran dari karbon teraktivasi ampas teh termasuk dalam kategori nano karbon (Najma, 2012; 
Xu et al., 2008) dengan ukuran partikel 20- $\quad 40 \mathrm{~nm}$.

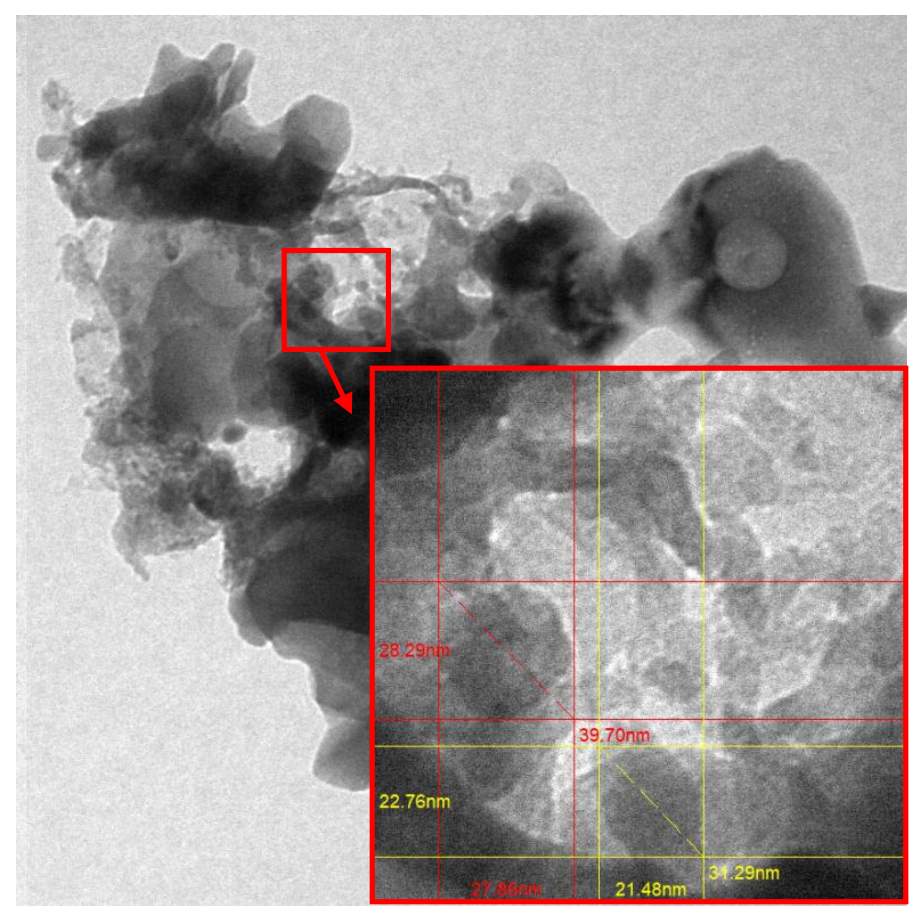

Gambar 4. Citra TEM Karbon Ampas Teh Teraktivasi

\section{Kesimpulan}

Hasil identifikasi dengan spektrofotometer FTIR menunjukkan bahwa karbon teraktivasi hasil sintesa dari ampas teh mengandung gugus fungsi $\mathrm{O}-\mathrm{H}$, $\mathrm{C}-\mathrm{O}, \mathrm{C}-\mathrm{H}, \mathrm{C}=\mathrm{C}, \mathrm{C}=\mathrm{O}$ dan $\mathrm{C} \equiv \mathrm{C}$. Dari hasil XRD menunjukkan $\mathrm{C}$ graphite pada peaks $26,2^{\circ} ; 26,5^{\circ} ; 42,2^{\circ} ; 42,4^{\circ}$; dan $44,3^{\circ}$ dan hasil analisa TEM yang menunjukkan struktur yang tidak homogen berukuran 20$40 \mathrm{~nm}$.

\section{Daftar Pustaka}

Adinata, M.R., 2013. Pemanfaatan Limbah Kulit Pisang Sebagai Karbon Aktif. Universitas Pembangunan Nasional "Veteran", Jawa Timur.
Ahmaruzzaman, M., Laxmi Gayatri, S., 2010. Activated Tea waste as a potential Low cost adsorbent for the removal of p-Nitrophenol from wastewater. J. Chem.Eng.Data 55, 4614-4623.

https://doi.org/10.1021/je100117s

Fitria, V., Tjahjani, S., 2016. DARI TEMPURUNG KELUWAK ( Pangium edule ) DENGAN AKTIVATOR H 3 PO 4, in: Pembuatan Dan Karakterisasi Karbon Aktif Dari Tempurung Keluwak (Pangium Edule) Dengan Aktivator H3PO4. Jurusan Kimia FMIPA Universitas Negeri Surabaya, pp. 712. 
Girgis, B.S., Temerk, Y.M., Gadelrab, M.M., Abdullah, I.D., 2007. X-ray Diffraction Patterns of Activated Carbons Prepared under Various Conditions. Carbon Lett. 8, 95-100. https://doi.org/10.5714/CL.2007.8.2. 095

Güler, Ö., Boyrazlı, M., Başgöz, Ö., Bostanc1, B., 2017. The synthesis of carbon nanostructures from tea plant wastes. Can. Metall. Q. 56, 349-359. https://doi.org/10.1080/00084433.20 17.1345467

Hartini, Hidayat, Y., Mudjijono, 2015. Study Pore Characterization of $\gamma$ Alumina - Activated Carbon Composite made of Cassava Peels (Manihot esculenta Cranz). ALCHEMY 11, 47-57. https://doi.org/10.20961/alchemy.v11 i1.106

Mahvi, A.H., Naghipour, D., Vaezi, F., Nazmara, S., 2005. Teawaste as An Adsorbent for Heavy Metal Removal from Industrial Wastewaters. Am. J. Appl. Sci. 2, 372-375. https://doi.org/10.3844/ajassp.2005.3 72.375

Manullang, S.P., 2010. Pengaruh Pemberian Ampas Teh (Camellia sinensis) dalam Pakan terhadap Analisis Usaha Domba Lokal Jantan Lepas Sapih selama 3 Bulan Penggemukan. Universitas Sumatra Utara, Medan.
Najma, 2012. Pertumbuhan nanokarbon menggunakan karbon aktif dari limbah kulit pisang dengan metode pirolisis sederhana dan dekomposisi metana. Universitas Indonesia, Depok.

Nasri, N.S., Basri, H., Garba, A., Hamza, U.D., Mohammed, J., Murtala, A.M., 2015. Synthesis and Characterization of Low-cost Porous Carbon from Palm Oil Shell via $\mathrm{K} 2 \mathrm{CO} 3$ Chemical Activation Process. Appl. Mech. Mater. 735, 36-40. https://doi.org/10.4028/www.scientifi c.net/AMM.735.36

Pari, G., Santoso, A., Hendra, D., Buchari, B., Maddu, A., Rachmat, M., Harsini, M., Heryanto, T., Darmawan, S., 2013. Karakterisasi Struktur Nano Karbon Dari Lignosellulosa. J. Penelit. Has. Hutan 31, 75-91. https://doi.org/10.20886/jphh.2013.3 1.1.75-91

Sahara, E., Sulihingtyas, W.D., Mahardika, I.P.A.S., 2017. Pembuatan dan Karakterisasi Arang Aktif dari Batang Tanaman Gumitir (Tagetes erecta) yang Diaktivasi dengan H3PO4. J. Kim. 11, 1-9.

Sastrohamidjojo, H., 2001. Dasar-Dasar Spektroskopi, 2nd ed. Liberty Yogyakarta, Yogyakarta.

Shamsuddin, M.S., Yusoff, N.R.N., Sulaiman, M.A., 2016. Synthesis and Characterization of Activated Carbon Produced from Kenaf Core Fiber 
Using H3PO4 Activation. Procedia

Chem. $\quad 19, \quad 558-565$.

https://doi.org/10.1016/j.proche.2016

.03 .053

Subagio, A., Pardoyo, Priyono, Yudianti, R., Rowi, K., Taufiq, M.I., 2013. Pemurnian Carbon Nanotubes menggunakan Larutan HNO3 dengan metode Pencucian Biasa dan Reflux. J. Fis. Indones. XVII, 1-4.

Syaifudin, L.N., 2013. Pemanfaatan Limbah Sayur-Sayuran untuk Pembuatan Kompos dengan Penambahan Air Kelapa (Cocos nucifera) dan Ampas Teh Sebagai Pengganti Pupuk Kimia Pada Pertumbuhan Tanaman Semangka(Citrullus vulgaris L ). Universitas Muhammadiyah Surakarta.

Tutuş, A., Kazaskeroğlu, Y., çiçekler, M., 2015. Evaluation of tea wastes in usage pulp and paper production. BioResources 10, 5395-5406. https://doi.org/10.15376/biores.10.3. 5395-5406

Wibowo, S., Syafi, W., Pari, G., 2011. Karakterisasi Permukaan Arang Aktif Tempurung Biji Nyamplung. Makara, Teknol. 15, 17-24.

Xu, Y.J., Weinberg, G., Liu, X., Timpe, O., Schlögl, R., Su, D.S., 2008. Nanoarchitecturing of Activated Carbon: Facile Strategy for Chemical Functionalization of the Surface of Activated Carbon. Adv. Funct.
Mater. $\quad 18, \quad 3613-3619$. https://doi.org/10.1002/adfm.200800 726 